\title{
A EVOLUÇÃO HISTÓRICA DAS AÇÕES COLETIVAS PASSIVAS E A NECESSIDADE DE CONTROLE DAS COLETIVIDADES
}

\author{
Renato Woolley de Carvalho Martins ${ }^{1}$
}

MARTINS, R. W. de C. A evolução histórica das ações coletivas passivas e a necessidade de controle das coletividades. Rev. Ciênc. Juríd. Soc. UNIPAR. Umuarama. v. 18, n. 1, p. 105-119, jan./jun. 2015.

RESUMO: Este artigo apresenta os resultados de um estudo da evolução histórica das ações coletivas passivas que visa a analisar a necessidade de controle das coletividades. Para tanto, far-se-á uma abordagem do direito processual coletivo sob o enfoque das ações coletivas passivas, ou seja, em vez de um litigante coletivo ajuizando ação em face de um réu individual, teremos um autor individual ou um autor coletivo, ajuizando a ação em face de um réu coletivo.

PALAVRAS-CHAVE: Ação coletiva passiva; Evolução histórica; Coletividades. Necessidade de controle.

\section{INTRODUÇÃO}

Este trabalho, utilizando-se do método dedutivo, apresentará uma abordagem de direito processual coletivo sob o enfoque das ações coletivas passivas, ou seja, em vez de um autor coletivo ajuizando ação em face de um réu individual, na proteção de direitos e interesses difusos, coletivos stricto sensu ou individuais homogêneos, teremos um autor individual ou coletivo ajuizando a ação em face de um réu coletivo.

Não ofereceremos aqui uma evolução histórica segundo a ordem cronológica, mas segundo a sucessão das ideias. As fases ou estádios algumas vezes são simultâneos em suas manifestações e outras vezes aparecem invertidas no tempo da escrita.

Mas esses períodos históricos e seus desenvolvimentos internos inegavelmente se apresentarão como implicação dialética, ou seja, não poderão ser apreendidos, por nosso leitor, isolados uns dos outros.

Com efeito, trataremos da evolução histórica das ações coletivas passivas desde suas origens remotas no direito romano com as actiones populares e os interditos, passando pelo período medievo, destacando-se, na Inglaterra, as

DOI: https://doi.org/10.25110/rcjs.v18i1.2015.5414

${ }^{1}$ Procurador do Estado de Mato Grosso do Sul, Professor da Escola Superior da Magistratura de MS, Especialista em Processo Civil (PUC-SP), Especialista em Processo Civil (INPG-SP), Especialista em Direito do Estado e das Relações Sociais (UCDB-MS), Mestrando em Processo Civil (UNIPAR - Umuarama - PR). 
primeiras ações coletivas passivas de que se têm informação.

Em seguida, passaremos em revista os aspectos que reputamos mais relevantes no período moderno caracterizando: o individualismo-liberal que acabou por refrear o movimento de desenvolvimento das ações coletivas; a consciência de classe, momento de especial importância para o estudo das ações coletivas passivas e os movimentos de acesso à justiça da doutrina italiana.

No período contemporâneo, abordaremos o atual desenvolvimento do direito processual coletivo tradicional e, tendo em linha de consideração os fatos mais marcantes dessas linhas evolutivas, teceremos algumas considerações acerca da necessidade do controle das coletividades por meio das ações coletivas passivas.

É o que veremos nos capítulos que seguem.

\section{O DIREITO ROMANO}

Paula (2015, p. 27) ao discorrer sobre a jurisdição na idade antiga afirma: "Não se tem registro dos povos pré-históricos a respeito de uma atividade que se assemelhasse à jurisdicional"

E continua o citado autor:

Porém, como atividade jurídica, a jurisdição foi melhor estudada no direito romano. Nos primeiros tempos de Roma, o rei exerce concentradamente a função de juiz. Na República, a magistratura é colocada a cargo de dois cônsules e, em 387 a.C., institui-se a figura do pretor para cuidar da administração da justiça (PAULA, 2015, p. 27).

Os interditos e as ações populares romanas são apontados pela doutrina como a origem remota da defesa dos direitos transindividuais (NERY JUNIOR, 2002, p.601).

Neste ensejo temos como mais importante, do que a conceituação jurídica dos institutos romanos a pouco referidos, a referência deles como instrumentos de tutela coletiva de direitos.

Não desconhecemos também aqueles que desconsideram essa origem "remota" das ações coletivas no direito romano, sobretudo por conta da enorme diferença daqueles instrumentos com aquilo que conhecemos hoje como processo coletivo e sua adequada tutela (MENDES, 2014).

Todavia, não temos como determinante, a ponto de não fazer referência neste trabalho, a não-correspondência do conceito da ação coletiva e de tutela coletiva concebida hoje, à luz do ordenamento jurídico vigente, com aquele praticado pelo direito romano, sobretudo por termos em conta, que a tutela do objeto de direito material (pretensão) é a mesma em ambos os períodos evoluti- 
vos, ainda que a maneira de efetivá-lo seja diferentes - até mesmo por conta do desenvolvimento do direito processual coletivo como ciência autônoma, razão por que estamos com aqueles que consideram o direito romano como a gênese das ações coletivas passivas.

Destarte, por meio das ações populares e dos interditos as "coisas públicas" poderiam ser objeto de tutela judicial coletiva promovidas pelo cidadão romano na medida em que o pouco desenvolvimento da concepção do "Estado" àquela época passava ao cidadão o forte sentimento de que a res publica lhe pertencia e dizia respeito a todos os membros da Roma Antiga (MANCUSO, 2003, p. 42).

Nada obstante a tutela judicial coletiva fosse demandada pelo indivíduo o provimento jurisdicional, coberto pelo manto da coisa julgada, possuía efeitos erga omnes.

Por fim, afirma o Professor Mancuso (2003, pp. 47-48), que as ações populares romanas não sobreviveram à idade média, por conta do autoritarismo feudal, das monarquias absolutistas e da religiosidade aterrorizante da Santa Inquisição.

\section{O PERÍODO MEDIEVAL}

No período medievo, feudal ou senhorial, mais especificamente no direito anglo-saxão, registraram-se as primeiras ações coletivas passivas de que se tem notícia.

Assim como no direito romano, no período medieval, a concepção de indivíduo, ser-humano titular de direitos e obrigações na ordem civil, se confunde com a ideia de comunidade, na qual aquele estava inserido, razão por que não havia conflitos acerca da legitimidade processual para demandar ou ser demandado nas ações coletivas (LEAL, 1998, p. 26).

Não havia um desenvolvimento do direito processual como ciência autônoma razão por que não se indagava da legitimidade do indivíduo na defesa de interesses que diziam respeito a toda uma coletividade ou agrupamento humano.

Também não se concebia nesse período um direito uno provindo de uma fonte estatal, ou seja, do Estado. O direito tinha fontes produtoras diversas na sociedade.

Com efeito, as cortes aldeãs, reais e eclesiásticas, recebiam, processavam e julgavam ações contra coletividades de pessoas sem adentrar a questão da representatividade adequada do grupo, por aqueles que se apresentavam em juízo, fosse no polo ativo ou no polo passivo da demanda (MAIA, 2009).

No período medieval já podemos vislumbrar, e essa percepção vai ser importante no desenvolvimento de nossa pesquisa, que o reconhecimento de uma 
comunidade como grupo, verbi gratia uma pequena aldeia, formada pelos trabalhadores da terra, partia de fora para dentro, ou seja, o grupo por si não se autointitulava como portador de uma identidade própria, distinta de seus membros. Esse reconhecimento se dava pela sociedade, mas ainda de uma maneira pouco científica.

Por esta razão, afirma Diogo Campos Medina Maia, em obra sobre a ação coletiva passiva:

Por não haver uma consciência de classe ou ideia de indivíduo bem desenvolvida, e por carecer de estudos processuais a respeito da representatividade destes entes: as ações coletivas eram propostas e julgadas nos moldes das demandas individuais, sem maiores indagações. Desta forma, as ações coletivas passivas medievais apareciam sem restrição, com a mesma importância e efeitos da ação coletiva dita ativa (MAIA, 2009, pp. 13-140).

O primeiro registro de ação coletiva passiva data do ano de 1199, quando, em Inglaterra, na Corte Eclesiástica de Canterbury, o Pároco Martin de Barkway, ajuizou uma ação coletiva em face dos paroquianos de Nuthampstead.

Segundo os dados históricos a ação versava sobre a necessidade de se colocar diariamente um pastor para celebrar as missas na capela de Nuthampste$a d$, recém-adjudicada à paróquia de Barkway (MAIA, 2009, p. 14).

O segundo registro diz respeito a uma ação coletiva passiva ajuizada por três aldeões, em nome próprio e de toda a comunidade de Helpingham em face dos habitantes de Donington e Bykere, identificando no polo passivo apenas alguns habitantes daquelas duas localidades.

O objeto da demanda dizia respeito a corresponsabilidade dos aldeões de Donington e Bykere na manutenção de diques (MENDES, 2014, pp. 49-50).

Como adrede referido, vivenciava-se também neste período um sincretismo processual em que o direito processual se confundia com o direito material.

Nos períodos seguintes (moderno e contemporâneo) a ação coletiva passou a ser enfrentada de maneira diferente da tratada até aqui, sobretudo em relação à questão da legitimidade para figurar no processo muito por conta do desenvolvimento do direito processual como ciência autônoma. Com efeito.

\section{O PERÍODO MODERNO}

A transição para o período moderno passou pela valorização do indivíduo, como ser humano titular de direitos e deveres na ordem jurídica, considerado como ser dotado de dignidade. Neste período o indivíduo como foi destacado de sua comunidade. 
Passando do modo de vida feudal para o capitalismo, a Revolução Francesa e os pensamentos iluministas influenciaram o modo de pensar o direito processual e, segundo a doutrina, determinaram a redução de importância da figura do grupo na sociedade de sua época. O processo civil individual ganha destaque e proeminência.

Para Hespanha (1997, pp. 150-151), o individualismo emergente na transição do período moderno para o contemporâneo permitiu a dissociação do conceito de indivíduo da ideia de comunidade, na qual o homem estava inserido.

Daí porque o individualismo-liberal acabou por refrear o movimento de desenvolvimento das ações coletivas de modo que se passou a exigir uma justificação que permitisse ao indivíduo representar (representação) em juízo os interesses de toda uma comunidade, ausentes na relação processual.

Assim, pode-se concluir que parte do desinteresse pelas ações coletivas no período moderno também se deveu à estrutura processual individualista moldada à época.

Esse estado de coisas perdurou, segundo a doutrina, até meados do século XX, quando do surgimento das class actions nos EUA e do retorno das ações coletivas na Inglaterra (MENDES, 2014).

\section{O PERÍODO CONTEMPORÂNEO}

Neste período, sobretudo pela intensificação das relações sociais, perceberemos o fortalecimento e o desenvolvimento das ações coletivas tais quais as conhecemos hoje.

$\mathrm{Na}$ economia capitalista pós-revolução industrial a ideia de que o indivíduo, isoladamente considerado, não possuiria a força necessária para a defesa de seus interesses em comparação com a sua associação em grupo, sobretudo pela conscientização disso pela classe trabalhadora, unida na luta por seus direitos fundamentais contra as péssimas condições de trabalho da época, fez surgir uma comunidade, agora com consciência de sua importância, situada entre o indivíduo e o Estado.

Mas devemos fazer uma advertência: aqui, no período contemporâneo, a consciência de classe é aferida de dentro para fora, ou seja, o próprio agrupamento, por força das contingências sociais, assume essa sua condição na sociedade (subjetiva) enquanto que, no período da Roma Antiga e no período Medieval a "etiqueta designativa" era conferida de fora para dentro (objetiva) na medida em que o grupo não possuía esse discernimento e a sociedade é que a reconhecia como uma comunidade.

A consciência de classe, em sua acepção subjetiva, e o surgimento de conflitos coletivos em época até então marcada por litígios individuais desempe- 
nhou um importante papel no estudo das ações coletivas passivas e a necessidade de controle das coletividades.

No Brasil, a tutela coletiva de direitos encontra sua gênese com os métodos de solução de conflitos coletivos do trabalho, pelos Conselhos Mistos e Permanentes de Conciliação em 1931, que evoluíram para os dissídios coletivos.

Desse modo, a Consolidação das Leis Trabalhistas foi marco importante no Direito Processual Coletivo, pois além de possibilitar a solução judicial de conflitos coletivos, permitia que a coletividade figurasse no polo passivo e se sujeitasse aos efeitos da coisa julgada, vinculando individualmente os membros desses grupos, sem a necessidade de que se fizessem presentes no processo.

Passo seguinte, registra-se o contexto social do pós-segunda guerra mundial, que caracterizado pelo grande progresso econômico e suas consequências, como o urbanismo desenfreado e o incremento populacional, promoveu a intensificação das relações sociais e a criação de uma verdadeira sociedade de massas (GRAVONSKI, 2005, p. 18).

O Professor Luiz Fernando Coelho, num contexto de fundamentação científica da teoria crítica do direito, citando Herbert Marcuse, muito bem nos retrata a caracterização do período:

Marcuse denuncia esse fetichismo na sociedade tecnocrática contemporânea, onde, a despeito da extraordinária melhoria dos padrões de vida nos países mais ricos economicamente, a alienação se faz presente na sociedade pós-industrial através do consumismo. É que a sociedade tecnológica tende a criar falsas necessidades e satisfações também falsas, necessidades que são impostas ao indivíduo por interesses particulares; como diz Marcuse, a maioria das necessidades comuns de descansar, distrair-se, comportar-se e consumir de acordo com os anúncios, pertence a essa categoria de falsas necessidades (MARCUSE, 1982 apud COELHO, 1991, p. 140).

A evolução social do período foi determinante no surgimento de novos interesses, interesses estes que não diziam respeito a uma única pessoa mas, a um só tempo, a todos elas.

Nesse contexto, com o início da internacionalização dos direitos do homem conferido pela Declaração Universal dos Direitos Humanos, aprovada pela Assembleia Geral das Nações Unidas em 1948, e mais tarde, pela Conferência Internacional sobre o Meio Ambiente Humano, realizado em 1972, em Estocolmo, possibilitou o reconhecimento dos direitos fundamentais de terceira dimensão como o direito de todas as gerações, presentes e futuras, a um meio ambiente sadio, impulsionando, desse modo, o desenvolvimento e sistematização do direito processual coletivo (WOLKMER, 2003, p. 9), decorrente das fortes críticas 
contra a ineficácia do direito processual individual então vigente para tutelas desses direitos e interesses.

Bem resumindo o que até aqui foi dito, afirma Diogo Campos Medina Maia, em obra sobre a ação coletiva passiva:

A preocupação com os problemas da tutela dos direitos coletivos, todavia, não eclodiu de uma hora para outra, foi resultado de um processo de evolução marcado pelos efeitos do pós-guerra na vida social, pelo reconhecimento dos direitos difusos no panorama mundial e pela consciência da inaptidão do direito processual clássico em resolver conflitos coletivos (MAIA, 2009, pp.13-14).

Atendendo a esses reclamos registra-se o movimento de acesso à justiça como um dos responsáveis pelo desenvolvimento da tutela coletiva nos sistemas romano-germânicos, que, segundo a doutrina, se encontravam relativamente atrasados em relação à tutela coletiva de direitos dos ordenamentos jurídicos anglo-saxônicos.

O movimento de acesso à justiça, instigado pelo professor italiano Mauro Cappelletti, tratava das três ondas de acesso à justiça, que estavam sendo implementadas para a solução dos grandes problemas da justiça em todo o mundo (CAPPELLETTI; GARTH, 1998).

A tutela coletiva na proteção dos direitos transindividuais foi abordada na segunda onda, mas tratada na concepção da ação coletiva ativa, posto que à esta época, os grupos mal se organizavam para defenderem-se de lesões aos seus interesses razão pela qual muito menos forças possuíam para provocar lesões aos interesses de outrem.

Nesse período, o direito processual coletivo no Brasil, também tendo por base a defesa, dos interesses e direitos difusos, coletivos e individuais homogêneos foi desenvolvido e estruturado com base na legislação e doutrina italianas, e esta por sua vez, desenvolveu-se inspirado em influências estrangeiras, como as das experiências norte-americanas.

Destarte, apesar da inegável pluralidade de leis a compor o microssistema coletivo brasileiro, a doutrina parece tranquila no sentido de apontar como núcleo duro desse microssistema a Lei da Ação Civil Pública e o Código de Defesa do Consumidor (NEVES, 2012, p. 466).

Vejamos então, em apertada síntese, o corpo legislativo formador de nosso microssistema processual coletivo e suas principais contribuições.

A Lei da Ação Popular, n. ${ }^{\circ}$ 4.717/1965, foi a primeira lei que indiscutivelmente tratou de tutela coletiva no ordenamento brasileiro, trazendo em seu bojo significativas inovações, dentre elas, poderíamos citar a diferenciada forma de legitimidade ativa, conferida ao cidadão, portador de título eleitoral, a possi- 
bilidade de o réu virar autor, legitimidade bifronte, e a coisa julgada secundum eventum probationis.

O segundo diploma legislativo coletivo apontado pela doutrina especializada é a Lei da Ação Civil Pública, n. ${ }^{\circ} 7.347 / 1985$, que consagrou a tutela dos direitos difusos e coletivos, como os direitos do consumidor, meio ambiente, patrimônio histórico e cultural.

Elevar o direito material coletivo ao âmbito dos direitos fundamentais foi obra da Constituição Cidadã, de 5 de outubro de 1988.

A Constituição Federal, de 5 de outubro de 1988, ampliou o cabimento da ação popular, tutelando tanto os bens materiais que compõem o patrimônio público como também os bens imateriais, tais como a moralidade administrativa, o meio ambiente etc. Também concedeu, a Bíblia Política de nosso Estado, ao Ministério Público, como função institucional, a promoção do Inquérito Civil e a legitimidade, na condição de co-legitimado, para proposição da Ação Civil Pública.

Lembremos que em 1988 ainda havia a limitação da tutela a algumas espécies de direitos coletivos em razão da previsão do art. $1 .^{\circ}$ da LACP, de forma que a previsão constitucional foi inovadora ao não atrelar a atuação ativa do Ministério Público a qualquer espécie de direito coletivo lato sensu. Por fim, previu a Carta Magna o mandado de segurança coletivo, regulamentado pela Lei $12.016 / 2009$.

Dentro deste quadro normativo não poderíamos deixar de anotar a Lei 8.078/1990, o Código de Defesa do Consumidor. O diploma legal passou a prever que qualquer direito difuso ou coletivo poderia ser objeto de tutela coletiva, afastando aquela ideia restritiva da Lei da Ação Civil Pública, ampliando, desse modo, o âmbito de proteção coletiva em juízo. Por outro norte foi estendida aos direitos individuais homogêneos a tutela por meio do processo coletivo.

No direito norte-americano, do sistema anglo-americano, as ações coletivas passivas, encontraram um desenvolvimento e sistematização dignos de nota.

Foi na tradição anglo-saxônica que o desenvolvimento das ações coletivas passivas recebeu maior contribuição, sobretudo do direito processual coletivo estadunidense com a previsão normativa das defendant class action.

Para Elton Venturi:

Diferentemente do que se passou com a consagração da tutela jurisdicional dos direitos metaindividuais em alguns países de commom Law, talhada através da experiência acumulada pelos tribunais ao longo de décadas, no Brasil a sua introdução se deu abruptamente - constatação que ajuda a explicar (sem justificar) o distanciamento entre o modelo ideal e a prática forense brasileira, por vezes reacionária e 
insensível à novidade representada pela conceituação e regulação da defesa dos novos direitos (VENTURI, 2007, p. 18).

No leading case (Smith v. Swormstedt), citado por (MAIA, 2009, pp.3435), observaremos a vinculação de uma coletividade aos termos de uma decisão proferida pela Suprema Corte dos Estados Unidos, incluindo os demais membros dessa coletividade ausentes no processo coletivo, mas que restaram vinculados ao que decidido judicialmente.

Nesse precedente, a coletividade vinculada figurava no polo passivo de uma ação duplamente coletiva: seis pessoas, entre as quais figurava Smith, representando aproximadamente 1.500 pastores da Igreja Metodista Episcopal do Sul (originada da cisão da Igreja Metodista Episcopal Nacional), exerceram seu direito de ação em face dos pastores que restaram na igreja originária da cisão, em nome de apenas três pessoas, entre eles Swormstedt, que representavam outros mais de 3.000 pastores.

O objeto da ação era a recuperação da propriedade da porção de um fundo, originariamente instituído pela Igreja Metodista Episcopal Nacional antes da cisão, e que, após a separação, foi negado aos pastores da Igreja do Sul sob o fundamento de que, se a cisão havia sido voluntária, nada seria devido aos pastores da nova Igreja Sulista.

A Suprema Corte Estadunidense reformou a decisão originária que havia julgado extinto o processo sem resolução de mérito. Em seu voto, o $\mathrm{Mr}$. Justice Nelson asseverou que era necessário haver possibilidades em que, por conveniência e para prevenir ineficácia do provimento jurisdicional, a corte de equidade deveria permitir a parte dos interessados, representar toda a coletividade, com efeito vinculante da decisão judicial a todos, como se estivessem presentes perante a corte (MAIA, 2009, p. 34-35).

Em geral, a estrutura da regra 23 do Código de Processo Civil Federal norte-americano (Federal Rules of Civil Procedure), que trata das class actions na Justiça Federal, é simétrica, não fazendo distinção entre autor e o réu no litígio coletivo, com a característica de se verificar a representatividade adequada das partes e também dos patronos das coletividades.

Nesse sentido, até então, não se pensava em submissão de agrupamentos, como grupos, classes ou categorias de pessoas, a uma decisão judicial que contrariasse seus interesses quando lesionados ou ameaçados de lesão direitos de outrem.

Colocado até aqui o desenvolvimento da defesa em juízo dos interesses e direitos metaindividuais, no contexto atual surge a necessidade de controle das coletividades, por meio das ações coletivas passivas. Com efeito. 


\section{A NECESSIDADE DE CONTROLE DAS COLETIVIDADES}

O reconhecimento de novos direitos e interesses no período moderno; o ressurgimento, com nova roupagem jurídica, do grupo, da coletividade, e sua autoconsciência de classe, como titular (legitimado extraordinário) desses interesses e direitos metaindividuais, com o consequente desenvolvimento de novos procedimentos para a sua adequada tutela, até por conta de nossa realidade social, fez premente a necessidade de "proteção" dessas coletividades.

E isso foi feito. Nossa legislação processual civil coletiva e sua consolidação em mais de vinte anos a tornou um poderoso instrumento de efetivação de direitos e interesses difusos, coletivos e individuais homogêneos lesados ou ameaçados de lesão.

Todavia não chamou a atenção dos operadores do direito, como se disse alhures, a consideração de que também essas coletividades ou agrupamentos humanos poderiam violar direitos de outrem e de que tais conflitos uma vez configurados poderiam ficar à margem da jurisdição.

Nesse sentido, calha à fiveleta o escólio do Professor Doutor Jônatas Luiz Moreira de Paula, em obra sobre Democracia e Jurisdição, verbo ad verbum:

Geralmente quando se refere à democracia material individual estar-se-á repercutindo uma gama de interesses em benefício a uma ou a poucas pessoas. Todavia, não se pode afirmar que os interesses individuais ocorrem em detrimento dos interesses sociais ou coletivos sem que incorra em leviandade. Dentro de um sistema capitalista, se torna mister que interesses individuais ganhem proteção juspolítica para a sobrevivência do próprio sistema, eis que os avanços econômicos, científicos, culturais, sempre principiaram a partir de metas de indivíduos, superando um establishment de um dado momento cultural. Obviamente, os desvios, os exageros, o uso nocivo de interesses individuais sobre os interesses sociais ou públicos, acabam por impor limites a esses interesses, e tanto pode ocorrer o contrário, quando interesses de massas e os interesses públicos geram um mal à sociedade se arbitrariamente criam restrições indevidas aos interesses individuais. $\mathrm{O}$ equilíbrio entre essas repercussões de democracia material é uma receita que necessita de constante atualização, para a preservação da democracia e da própria vida em sociedade (PAULA, 2014, p. 80, grifo nosso).

A doutrina registra que o controle das coletividades na evolução histórica das ações coletivas passivas, seja no direito anglo-americano, seja no direito romano-germânico, se efetivou de duas maneiras, quais sejam, ou por meio 
da Lei, como por exemplo, utilizando-me do referencial trabalhista brasileiro, da disciplina normativa dos Sindicatos e da disciplina do direito de greve dos trabalhadores ou por meio da força policial do Estado no sentido de repremir movimentos contrários ao establishment de um dado momento cultural de uma sociedade.

A realidade social mudou e hoje estamos cercados de situações conflituosas coletivas passivas que clamam pela jurisdição no sentido de controle das coletividades. Senão, vejamos.

Ações judiciais movidas pelo Ministério Público do Estado de São Paulo contra as torcidas organizadas Mancha Verde, Tricolor Independente e Gaviões da Fiel, resultaram na extinção dessas associações na medida em que, em verdadeiro desvio de finalidade, se transformaram em grupos criminosos de estímulo a violência e à barbárie.

No processo judicial aviado para cancelar o registro da associação Grêmio Gaviões da Fiel Torcida, o pedido foi julgado improcedente em primeira instância, mas reformado em grau de apelação cível.

Pela leitura da parte dispositiva do acórdão verifica-se que, nada obstante, ter havido a extinção da associação ré, os efeitos da coisa julgada repercutiram diretamente sobre os associados e seu direito fundamental de livre associação o que nos leva a conclusão de que as partes que figuraram como réus nos processos não foram exatamente os titulares dos direitos materiais correspondentes; mas, sim, entes coletivos que representaram judicialmente os interesses daqueles em face da impossibilidade de se individualizar cada um dos membros das coletividades designadas responsáveis pelos atos ilícitos de que se teve notícia.

No exemplo supramencionado, numa perspectiva tradicional de um processo individualista, a ser regrado pelo Código de Processo Civil de 1973, a figura da legitimidade processual, do litisconsórcio passivo necessário, de aplicação quase impossível, e a necessidade de extensão subjetiva dos efeitos da coisa julgada àqueles que não estavam presentes na demanda, por certo, sob esta perspectiva, não encontrariam a adequada tutela jurisdicional.

Não temos dúvidas em afirmar que sob este enfoque é que foi examinada a demanda supra em primeiro grau de jurisdição na medida em que extinta sem a resolução de seu mérito e, sob a ótica da necessidade de controle das coletividades, fora analisada em segunda instância, verdadeiramente encarada como uma ação coletiva passiva razão por que ultrapassados óbices processuais referentes ao processo individual.

Como não deixar de pensar em controle das coletividades, e aqui não exercemos qualquer juízo das postulações reivindicadas, por meio das ações coletivas passivas, quando todos somos lesados em nossos direitos e interesses de livre circulação - naquilo que Canotilho (2003, p. 451) denomina liberdade de 
deslocação -em todo o território nacional, por meio das rodovias federais e estaduais, pela categoria dos Caminhoneiros ou do Movimento dos Trabalhadores Sem Terra?

No município de Baturité no Ceará, o Ministério Público do Estado ajuizou ação civil pública em face de alguns comerciantes identificados, alocando-os no polo passivo da demanda, e em face de todos os comerciantes da área central, estes representados adequadamente por aqueles, postulando ao Poder Judiciário que os réus (coletividade de comerciantes) se abstivessem de expor à venda seus produtos no passeio público na medida que impossibilitavam aos pedestres transitarem sobre as calçadas (VIOLIN, 2008, p.94).

Nessa ação, o Parquet exerceu uma pretensão coletiva em face de uma coletividade, qual seja, os comerciantes da cidade de Baturité. Assim, apresentasse uma abordagem de direito processual coletivo sob o enfoque das ações coletivas passivas, ou seja, em vez de um autor coletivo ajuizando ação em face de um réu individual, na proteção de direitos e interesses difusos, coletivos stricto sensu ou individuais homogêneos, teremos um autor individual ou coletivo ajuizando a ação em face de um réu coletivo.

Então, se sob o viés da necessidade de controle das coletividades, quando lesam ou ameaçam de lesão direitos de outrem, pensarmos em ação coletiva passiva, em representatividade adequada de interesses daquele grupo no polo passivo, dispensando, portanto, o comparecimento de todos aqueles que seriam atingidos em suas esferas jurídicas, para o exercício do contraditório e da ampla defesa, incidindo sobre todos eles a coisa julgada, teríamos verdadeiramente uma prestação jurisdicional efetiva, adequada e cumpridora do direito e garantia fundamental do princípio da inafastabilidade da jurisdição, previsto no inciso XXXV do artigo 5. ${ }^{\circ}$ da Constituição Federal da República Federativa do Brasil.

\section{CONCLUSÃO}

Pensamos que memórias ou histórias podem preparar para complicações, indagações e proporcionar desenvolvimento científico. Este o escopo de nosso trabalho ao afirmar que a tutela coletiva de direitos evoluiu de forma heterogênea em bases territoriais e sistemas jurídicos diversos, que foram desde a Roma Antiga até o direito coletivo atual.

Passamos do reconhecimento histórico e da prevalência dos "conflitos de massa" e do desenvolvimento processual coletivo apto a tutelar adequadamente esses interesses e direitos difusos, coletivos e individuais homogêneos para a necessidade de controle das coletividades que também lesionam interesses e direitos de outrem, sejam estes indivíduos ou coletividades no que denominamos de "conflitos entre massas". 
Em quadro conclusivo, é lícito verberar o reconhecimento de que as coletividades podem lesar direitos ou interesses razão por que mister a reapreciação dos institutos processuais coletivos numa perspectiva de tutela das situações jurídicas coletivas passivas.

Antônio Gidi posiciona sua preocupação com o tema da seguinte maneira:

Se é verdade que há alguns anos o direito brasileiro ainda não estava preparado para enfrentar os problemas envolvidos em uma ação coletiva passiva, o certo é que já chegou o momento de começar a pensar no assunto não somente de lege ferenda, como também, talvez, de lege lata (GIDI, 2007, p. 414).

Assim: "Verifica-se, desde então, a possibilidade juspolítica do Poder Judiciário em ingressar em temas em que até recentemente era-lhe falsamente afastado" (PAULA, 2011, p. 164).

Com efeito, o desiderato de nossas reflexões foi deixar antever ao leitor a necessidade premente de uma nova perspectiva no direito processual coletivo - a necessidade de controle das coletividades -, na medida em que podem lesar direitos e interesses de outrem, podendo, desse modo, figurarem como réus em ações coletivas passivas.

\section{REFERÊNCIAS}

GIDI, A. A class action como instrumento de tutela coletiva dos direitos. São Paulo: Revista dos Tribunais, 2007.

CAPPELLETTI, M.; GARTH, B. Acesso à justiça. Porto Alegre: S. A. Fabris, 1998.

COELHO, L. F. Teoria crítica do direito. 2. ed. Porto Alegre: S. A. Fabris, 1991.

GRAVONSKI, A. A. Das origens ao futuro da lei de ação civil pública: o desafio de garantir acesso à justiça com efetividade. In: MILARÉ, Edis (coord.). A ação civil pública após 20 anos: efetividade e desafios. São Paulo: Revista dos Tribunais, 2005.

HESPANHA, A. M. Panorama histórico da cultura jurídica europeia. Lisboa: Europa-América, 1997. 
CANOTILHO, J. J. G. Direito constitucional e teoria da Constituição. 7. ed. Portugal: Almedina, 2003.

LEAL, M. F. M. Ações coletivas: história, teoria e prática. Porto Alegre: Fabris, 1998.

MAIA, D. C. M. Ação coletiva passiva. Rio de Janeiro: Lumen Juris, 2009.

MANCUSO, R. de C. Ação popular. 5. ed. São Paulo: Revista dos Tribunais, 2003.

MENDES, A. G. de C. Ações coletivas no direito comparado e nacional. 4. ed. São Paulo: Revista dos Tribunais, 2014.

NERY JUNIOR, N. Ação civil pública no processo do trabalho. In: MILARÉ, Edis (Coord.). Ação civil Pública: lei 7.347/1985 - 15 anos. 2. ed. São Paulo: Revista dos Tribunais, 2002.

NEVES, D. A. A. Manual de processo coletivo. São Paulo: Método, 2012.

PAULA, J. L. M. de. Democracia e jurisdição. Curitiba: J. M. Editora, 2014. Instituições do processo civil e o Novo CPC. Curitiba: J. M. Editora, 2015.

. Teoria política do processo civil: a objetivação da justiça social. Curitiba: J. M. Editora, 2011.

VENTURI, E. Processo civil coletivo. São Paulo: Malheiros, 2007.

VIOLIN, J. Ação coletiva passiva fundamentos e perfis. Salvador: JusPodivm, 2008.

WOLKMER, A. C. Introdução aos fundamentos de uma teoria geral dos "novos" direitos. In:WOLKMER, A. C.; LEITE, J. R. M. (Org.). Os "novos" direitos no Brasil: natureza e perspectivas: uma visão básica das novas conflituosidades jurídicas. São Paulo: Saraiva, 2003. 


\title{
HISTORICAL EVOLUTION OF DEFENDANT CLASS ACTIONS AND THE NEED OF CONTROL OF COLLECTIVITIES
}

\begin{abstract}
This paper presents the results of a study on the historical evolution of defendant class actions that aim to analyze the need for controlling collectivities. For such, an approach to collective procedural law from the standpoint of the defendant class actions, that is, rather than a collective litigant filing a lawsuit against an individual defendant, there will be an individual author or a corporate author filing a lawsuit against a collective defendant.
\end{abstract}

KEYWORDS: Defendant class action; Historical development; Collectivities; Need of Control.

\section{EVOLUCIÓN HISTÓRICA DE LAS ACCIONES COLECTIVAS PASIVAS Y LA NECESIDAD DE CONTROL DEL COLECTIVO}

RESUMEN: Este artículo presenta los resultados de un estudio sobre la evolución histórica de las acciones colectivas pasivas, que busca analizar la necesidad de control del colectivo. Para tanto, se ha hecho un abordaje del derecho procesual colectivo bajo el enfoque de las acciones colectivas pasivas, o sea, en vez de un litigante colectivo, enjuiciando acción frente a un reo individual, tendremos un autor individual o un autor colectivo, enjuiciando la acción frente a un reo colectivo.

PALABRAS CLAVE: Acción colectiva pasiva; Evolución histórica; Colectivo. Necesidad de control. 